\title{
MUDANÇAS NA ESPACIALIDADE DA ESTRUTURA PRODUTIVA DO CEARÁ: UM ESTUDO DE SUAS MICRORREGIÕES NOS ANOS DE 2007 E 2017
}

\author{
Denis Fernandes Alves ${ }^{1}$ \\ Francisco do O' de Lima Júnior ${ }^{2}$ \\ Wellington Ribeiro Justo ${ }^{3}$
}

Resumo: Este estudo tem por objetivo estimar um Índice de Estrutura Produtiva do Ceará (IEPC) e identificar os principais fatores que explicam as características da estrutura produtiva do estado. Metodologicamente, foi utilizada a técnica estatística multivariada de análise fatorial, pelo método dos componentes principais. Os dados são de origem secundária da RAIS, IBGE e MDIC, para os anos de 2007 e 2017. Constataram-se importantes modificações na estrutura produtiva, observando uma ampliação de uma para quatro no número de microrregiões com alto grau de crescimento econômico no período, a saber: Fortaleza, Litoral de Camocim e Acaraú, Sobral e Cariri. O IEPC identificou que houve um processo de interiorização e crescimento das estruturas produtivas das microrregiões, embora ainda existam disparidades entre o interior e o litoral do estado.

Palavras-chave: Estrutura Produtiva. Análise Fatorial. IEPC. Microrregiões. Ceará.

\section{CHANGES IN THE SPACIALITY OF THE CEARÁ PRODUCTIVE STRUCTURE: A STUDY OF ITS MICRORREGIONS IN THE YEARS OF 2007 AND 2017}

Abstract: This study aims to estimate a Ceará Productive Structure Index (IEPC) and identify the main factors that explain the characteristics of the state's productive structure. Methodologically, the multivariate statistical technique of factor analysis was used, by the principal component method. The data are of secondary origin from RAIS, IBGE and MDIC, for the years 2007 and 2017. It was found important modifications in productive structure, observering an enlargement from one to four in the number of micro-regions with a high degree of economic growth in the period, namely: Fortaleza, Litoral de Camocim and Acaraú, Sobral and Cariri. The IEPC identified that there was a process of interiorization and growth of the productive structures of the micro-regions, although disparities still exist between the interior and the coastal of the state.

Keywords: Productive Structure. Factor analysis. IEPC. Microregions. Ceará.

\section{CAMBIOS EN LA ESPACIALIDAD DE LA ESTRUCTURA PRODUCTIVA DE CEARÁ: UN ESTUDIO DE SUS MICRORREGIONES EN LOS AÑOS 2007 Y 2017}

Resumen: Este estudio tiene como objetivo estimar un Índice de Estructura Productiva de Ceará (IEPC) e identificar los principales factores que explican las características de la estructura productiva del estado. Metodológicamente, se utilizó la técnica estadística multivariada de análisis factorial, por el método del

\footnotetext{
1 Universidade Federal de Pernambuco, Programa de Pós-Graduação em Economia - PIMES, Recife/PE, Brasil, denis_fernandes@outlook.com, https://orcid.org/0000-0003-3322-2075.

2 Universidade Regional do Cariri, Departamento de Economia, Crato/CE, Brasil, lima.junior@urca.br, https://orcid.org/0000-0002-6049-3893.

3 Universidade Regional do Cariri, Departamento de Economia, Crato/CE, Brasil, justowr@yahoo.com.br, https://orcid.org/0000-0002-4182-4466.
} 
componente principal. Los datos son de origen secundario de RAIS, IBGE y MDIC, para los años 2007 y 2017. Foram encontradas modificações significativas na estrutura produtiva, observando uma expansão de um para quatro no número de microrregiões com alto grau de crescimento econômico no período, a saber: Fortaleza, Litoral de Camocim e Acaraú, Sobral e Cariri. El IEPC identificó que ha un proceso de interiorización y crecimiento de las estructuras productivas de las microrregiones, todavía existen disparidades entre el interior y la costa del estado.

Palabras clave: Estructura productiva. Análisis factorial. IEPC. Microrregiones. Ceará.

\section{Introdução}

As transformações macroeconômicas advindas na segunda metade do século XX proporcionaram em seu bojo um conjunto de acontecimentos que, por sua vez, modificaram o caráter produtivo de muitos países. A economia brasileira foi profundamente marcada por essa reestruturação produtiva, sobretudo ao longo dos anos 1990 e início dos anos 2000 (DEDECCA; ROSANDISK, 2006).

Essas transformações que aconteciam na conjuntura econômica brasileira tiveram que superar certos desajustes regionais, em função maior da unificação dos mercados nacionais. Segundo Cano (1998), esse processo está associado à intensificação dos movimentos da industrialização, situado em sua maior parte na região Centro-Sul, mais especificamente no estado de São Paulo. Coube então, às demais regiões, sobretudo o Nordeste, passar a estimular e a diversificar suas atividades produtivas, através do aumento da produtividade e da inserção no mercado externo.

No estado do Ceará, por sua vez, a conformação das transformações com a ação coordenada do governo estadual, nos marcos da busca de modernização econômica foi conduzida pelo que convencionou chamar de "paradigma de gestão governamental mudancista" (LIMA JÚNIOR, 2014). Assim, a partir de meados da década de 1980, o Ceará passou por rápidas e profundas transformações de ordem política e institucional com significativa repercussão econômica (SOUSA, 2007).

Muito embora, o processo de industrialização e modernização tenha iniciado na capital cearense (Fortaleza), onde há maior concentração das atividades produtivas e situado no litoral, o que facilita o processo de escoamento da produção, ocorrem também transformações importantes no interior do estado. Segundo Pereira Júnior (2009) essas transformações inserem algumas outras cidades no circuito da produção industrial moderna, no qual a montagem de uma estrutura de equipamentos que garantam a fluidez da distribuição e consumo capitalista vai 
apontar para a mudança da infraestrutura estadual. Essa infraestrutura, cada vez mais volta-se ao avanço da inserção competitiva do Ceará, direcionando-se ao mercado nacional e internacional. Nesse sentido, os elementos que vão consolidar a reestruturação produtiva e territorial no Ceará estão diretamente ligados à política econômica implementada pelo Governo do Estado com foco nas suas diferenciações intra espaciais.

Em vista disso, a pergunta que problematiza o presente trabalho se dá no seguinte questionamento: será que as políticas de interiorização do desenvolvimento, têm de fato expressado mudanças nas atividades produtivas em nível de microrregiões? Quais as microrregiões de maior crescimento econômico?

A abrangência de entender como se espacializa, nas microrregiões cearenses, as determinações da reestruturação produtiva estão no cerne que motiva este trabalho. Um estudo sobre os fatores que determinam o padrão de desenvolvimento econômico ao nível de microrregiões evidencia não só o seu alcance, mas também as relações entre os fatores importantes na sua determinação. De acordo com Perobelli et al. (1999) e Rezende, Fernandes e Silva (2007), calcular potenciais de crescimento econômico tem por objetivo possibilitar conhecer melhor as características locais que compõem a região, bem como a dinâmica produtiva em estudo.

Daí a grande importância dos estudos relacionados à distribuição espacial. Já que se trata de um avanço em termos metodológicos dentro da economia regional, que permitem entender os processos de disparidades intra regionais em termos de estrutura produtiva no território, nesse caso o território cearense.

A hipótese que baliza responder a indagação acima é a acepção de que houve mudanças na estrutura produtiva e na espacialidade destas no estado Ceará, na comparação entre os anos 2007 e 2017. O recorte temporal é justificado por ser o período de uma década a partir do início do Governo Cid Gomes, onde o estado do Ceará apresentou, nessa etapa, uma taxa de crescimento econômico média de $11,2 \%$, a terceira maior do Nordeste segundo dados do IBGE, além de demarcar a consolidação de um modelo de condução político-econômica demarcada por este governo ${ }^{4}$.

Nesse sentido, o estudo tem por objetivo estimar um Índice de Estrutura Produtiva do Ceará (IEPC) e identificar as principais mudanças, grau de crescimento

4 Trata-se das etapas subsequentes, vis à vis à conjuntura econômica macro, do que se convencionou chamar de "Governo de Mudanças, instaurado no Ceará ainda na segunda metade da década de 1980 (LIMA JÙNIOR, 2014). 
econômico e a organização espacial das microrregiões mais desenvolvidas em termos de estrutura produtiva nos anos em estudo. No Nordeste, a escolha do estado do Ceará, é baseada em seu passado histórico de concentração das atividades mais produtivas na região litorânea o que provocou certos gargalos no desenvolvimento do interior do estado. O diferencial deste estudo é que se trata de uma análise microrregional e pioneira para o estado, diferentemente de outros estudos (REZENDE; FERNANDES; SILVA, 2007; PINHEIRO, 2009; MORAIS; SOBREIRA; LIMA, 2018).

Além desta introdução, o artigo está estruturado em outras seis seções. A segunda seção trata da economia cearense ao longo dos anos, como se deu processo de reestruturação produtiva e também das políticas de interiorização do desenvolvimento. Na terceira seção é abordada uma revisão de estudos empíricos recentes portando a análise fatorial em aspectos econômicos e regionais, seguido pela seção dos procedimentos metodológicos. Na quinta seção são apresentados os resultados e discussão e, por fim, na última seção têm-se as considerações finais.

\section{Economia do Ceará: reestruturação produtiva e políticas de interiorização}

Entre os anos de 1950 até meados dos anos 1980, a economia do Ceará atravessou uma etapa de diversificação e modernização produtiva com ação planejada governamental. Contudo, foi através de intervenções de organismos institucionais de fomento ao desenvolvimento regional, em especial a SUDENE, que - Ceará experimentou transformações mais sólidas e consistentes no seu quadro produtivo e na sua infraestrutura, por meio de ações de desenvolvimento via industrialização (AMORA, 1994).

Com o desgaste do nacional-desenvolvimentismo e da subsequente ação planejada de desenvolvimento regional emerge um novo momento. A fase de reestruturação produtiva sob os moldes de regulação capitalista e inserção competitiva, foi vislumbrada a partir de 1986, quando o Ceará passou por transformações internas visíveis na condução da política econômica e consolidada nos anos subsequentes, na denominada "Era Jereissati" com a entrada de um novo grupo político ao poder (ALVES et al., 2017).

Surge então, o interesse mais explícito do capital em desenvolver a industrialização, e também se torna possível o processo de enxugamento da máquina estatal com um novo projeto modernizante. Este movimento permitiu em 
tese o rompimento com o apadrinhamento político, que hierarquizava os cargos mais elevados da Secretaria do Estado (ARAÚJO, 2007; SILVA FILHO; QUEIROZ, 2009).

A análise da dinâmica setorial produtiva é relevante para a compreensão dos fatores que influenciam no processo de promoção do desenvolvimento da economia cearense. Todavia, a reestruturação ocorrida com mais consistência no país na década de 1990, teve repercussões acentuadas nas características da cadeia produtiva em todos os setores de atividade econômica. No que se refere ao comportamento cearense, ocorre que nos últimos 30 anos houve mudanças estruturais significativas na indústria, agricultura e serviços com a inserção de novas tecnologias e espraiamento da atividade no interior do estado, deste modo promovendo o desenvolvimento cearense.

Para Accioly (2009) as políticas de interiorização do desenvolvimento eram voltadas a atrair o capital nacional e estrangeiro. Dentre as ações do governo voltadas à interiorização do desenvolvimento, ressalta-se o fortalecimento das cidades médias, as políticas fiscais e os investimentos em infraestrutura urbana de modo a atrair tanto o capital nacional quanto o capital estrangeiro nas atividades industriais e turísticas, imobiliárias.

Segundo Vasconcelos, Almeida e Silva (1990) por meio das políticas de interiorização do governo ampliaram-se oportunidades de trabalho, políticas de desenvolvimento da educação e saúde, investimentos em setores de porte com poder multiplicador e ajuste fiscal, seguido de controle das despesas do estado. Tal movimento soma-se às ações do governo federal de 2003 em diante, que seguem o mesmo dínamo de espraiamento.

No Ceará os setores de destaques a partir de meados dos anos 2000, foram a indústria e serviços. Os segmentos de caráter primário, sobretudo das atividades agrícolas, foram fortemente impactados pela reestruturação econômica. Surge então a importância do agronegócio e dos agropólos frente aos segmentos geradores de renda no território cearense.

No que se refere ao setor terciário, o Ceará seguiu as transformações e passou por uma desconcentração em setores mais gerais tendo como diferencial o crescimento de municípios além da Região Metropolitana de fortaleza (RMF). O turismo nas microrregiões litorâneas, a consolidação da descentralização dos serviços públicos e a expansão do comércio estiveram à frente do movimento. Como observado, os serviços se constituíram no setor com menos prejuízos em termos de 
transformações nos últimos anos, não só no Ceará como no Nordeste e Brasil (ALVES, 2020).

Vale destacar que a retomada do consumo situada na recomposição de compra do salário mínimo, na ampliação dos salários médios, na retomada do crédito ao consumidor serviu de munição e a expansão ampliou o crescimento do comércio varejista principalmente das microrregiões interioranas. As redes de comércio varejistas e outros segmentos foram cada vez mais se espraiando pelo território estadual.

De modo geral, apesar da atração de empresas fornecedoras de componentes, os impactos locais se restringiram aos empregos diretos gerados. Os investimentos realizados na integração da cadeia produtiva ainda não têm sido suficientes para induzir a formação de aglomerações setoriais similares às de outras regiões do país. Por outro lado, também é preciso atentar para a qualidade destes empregos. A mão de obra, além de ser mais barata em relação às demais regiões, é contratada mediante práticas de flexibilização das relações de trabalho como as cooperativas de trabalho, conforme os estudos apresentados por Harvey (1990) indicando elevada vulnerabilidade.

\section{Evidências Empíricas}

Nas últimas três décadas, muitos pesquisadores e estudiosos têm empregado análises multivariadas mais aprofundadas, tendo como suporte importantes dados que demonstram evidências e comportamentos de crescimento e desenvolvimento de municípios, Regiões Metropolitanas, microrregiões, mesorregiões, entre outros recortes espaciais.

Os estudiosos Johnson e Wichern (1992) apresentaram técnicas de análise estatística multivariada aplicada que são referências na literatura desses estudos avançados. Já Haddad (1992) apresentou abordagens que visam os novos polos regionais de desenvolvimento, pautando-se nas técnicas de análise fatorial que visa identificar o comportamento e características desses locais. Nesse sentido, a técnica de análise fatorial tem sido bastante utilizada com o intuito principal de encontrar e entender certos padrões e determinantes do desenvolvimento de áreas estudadas, bem como ajuda no processo de tomada de decisão na área de promoção e alocação de investimentos regionais.

No artigo de Rezende, Fernandes e Silva (2007) o objetivo foi a definição dos potenciais de desenvolvimento dos municípios da região Sul do estado de Minas 
Gerais, por meio do método estatístico da análise fatorial. Os autores puderam estabelecer uma hierarquia entre os municípios estudados, assim como, definir os municípios com maiores ou menores potenciais de desenvolvimento industrial, comercial e de serviços, desenvolvimento social e desenvolvimento agropecuário.

Já Shikida (2010) elaborou um estudo sobre o desenvolvimento socioeconômico e agroindústria canavieira no Paraná. Por meio da análise fatorial através do Índice de Desenvolvimento Socioeconômico (IDS) procurou mostrar qual é o quadro de desenvolvimento socioeconômico existente num município paranaense que abriga a atividade agroindustrial canavieira, em que esta figura como força motriz desse município. Constatou-se a necessidade de se comparar o grau de desenvolvimento socioeconômico entre os 22 municípios pesquisados com um maior número possível de variáveis, reduzidos a um menor número de fatores.

Conquanto usar um ou outro indicador pode ser temerário para afirmar se uma localidade apresenta melhor ou pior situação que outra, pois se verificaram casos em que o mesmo local pode ser mais bem avaliado em um quesito e fraco em outro. Com efeito, coexistem usinas e/ou destilarias em municípios bem colocados no ranking estadual de desenvolvimento socioeconômico, da mesma forma que se verificam esses estabelecimentos em municípios com precária situação.

Xerxenevsky e Fochezatto (2011) e Lima e Maia (2015) desenvolveram estudos abordando a técnica de análise fatorial, de forma semelhante, construindo um índice de desenvolvimento socioeconômico dos municípios. Xerxenevsky e Fochezatto (2011) analisaram o desenvolvimento dos municípios da região do litoral do Rio Grande do Sul, os resultados mostraram que em termos relativos (variando de 1 a 100) o índice médio de desenvolvimento situou-se em 46,8. A ordenação segundo o grau de desenvolvimento evidencia que a maioria dos municípios possui baixos níveis de desenvolvimento. Já Lima e Maia (2015) nos estudos dos municípios sul-mato-grossenses para o ano de 2010, observaram que o índice de desenvolvimento socioeconômico, permitiu a realização da hierarquização e a classificação dos municípios. Constatou-se, que a maioria dos municípios apresenta um baixo índice de desenvolvimento (54,5\% do total) e verificaram também que os quatro municípios mais desenvolvidos do Mato Grosso do Sul são Campo Grande, Dourados, Três Lagoas e Chapadão do Sul e os quatro menos desenvolvidos são: Japorã, Tacuru, Paranhos e Dois Irmãos do Buriti.

Assim como Shikida (2010), outro estudo realizado no Paraná feito por Eberhardt, Gabriel e Kodama (2016) apresenta uma proposta de um indicador de 
desenvolvimento e sua aplicação no Oeste do Paraná. Constatou-se que as 14 variáveis selecionadas para o estudo explicam 70,39\% da variância total dos dados. As cidades que apresentaram melhores condições socioeconômicas são: Ibema, Cascavel, Cafelândia, Santa Terezinha de Itaipu e Toledo.

Morais, Sobreira e Lima (2018) analisaram as microrregiões brasileiras, na busca por um padrão e determinantes da estrutura urbana estando associada com melhores índices de desenvolvimento. Por meio da construção do Índice da Estrutura Urbana (IEU), observaram que o mesmo permitiu fazer um ranking das 558 microrregiões brasileiras e classificá-las em alto, médio e baixo grau de estrutura urbana. Metade das microrregiões, 50\%, foram classificadas com baixo grau de estrutura urbana, 14,69\% foram classificadas com alto grau de estrutura (estando a maior parte na região Sudeste, cerca de $92,68 \%$ ) e os outros $35,31 \%$ foram classificadas como microrregiões de médio grau de estrutura urbana.

Alves et al. (2018) investigaram a estrutura produtiva nas mesorregiões do Nordeste brasileiro utilizando a técnica de análise fatorial. Por meio da construção do Índice de Estrutura Produtiva do Nordeste (IEPN) os autores observaram que a maioria das mesorregiões possuem baixos níveis de produtividade. O índice também mostrou que há disparidades intraestaduais, como é o caso do Ceará em que há substanciais diferenças de estruturas produtivas entre as mesorregiões litorâneas e interioranas.

Além da questão metodológica, que não expõe a totalidade dos movimentos econômicos do desenvolvimento capitalista e suas expressões nestes espaços, tais trabalhos apresentam algumas limitações. $O$ fato de se considerar apenas com um único período de tempo permite apenas um retrato do desenvolvimento dos locais em estudo. No entanto, uma análise mais completa pode ser feita incluindo outros recortes temporais. Admite-se, também, que nem todas as dimensões do desenvolvimento foram contempladas. A despeito disso, a metodologia é pertinente, pois dispõe de vários pontos positivos, entre eles a ponderação para os fatores não é arbitrária, mas baseia-se na variância explicada de cada fator. Assim, a própria estrutura de correlação das variáveis explica o desenvolvimento e, também, é possível utilizar um grande número de variáveis, as quais podem ser resumidas em fatores (LIMA; MAIA, 2015).

A seção seguinte apresenta como foi empregada a técnica de análise fatorial no presente estudo. Como forma de melhorar a qualidade e a confiabilidade dos resultados é justificado o uso de dois recortes temporais, nesse caso 2007 e 2017. 
Favorecendo a aplicação de uma análise mais abrangente, robusta e completa em termos economia regional, além de contribuir para o debate atual.

\section{Procedimentos metodológicos}

Aspectos técnicos da Análise Fatorial

A técnica de Análise Fatorial ( $\mathrm{AF}$ ) tem como finalidade a redução do número original de variáveis, por meio da extração de fatores independentes, de tal forma que estes fatores possam explicar, de maneira simples e reduzida, o conjunto das variáveis originais. Essa técnica foi escolhida a fim de contornar o problema de multicolinearidade, já que a inserção de variáveis altamente correlacionadas entre si provocaria o seu surgimento. Em virtude disso, o método da análise fatorial objetivou extrair os fatores determinantes da estrutura produtiva. Com a obtenção dos escores foi possível construir um índice capaz de mensurar e categorizar os municípios cearenses em alto, médio e baixo grau de crescimento econômico da estrutura produtiva, dentre um conjunto de 24 variáveis potencialmente explicativas.

O método utilizado na AF foi o de componentes principais, que faz com que o primeiro fator contenha o maior percentual de explicação da variância total das variáveis, o segundo fator apresente o segundo maior percentual, e assim por diante (PINHEIRO, 2009).

Dentre os métodos de rotação ortogonal como Oblimin Direto, Equamax, Quartimax, Proporção Máxima e Varimax, foi utilizado este último. A rotação ortogonal propõe um giro de fatores para localizar aqueles de alta correlação e de baixa correlação. Segundo Pallant (2007) o Varimax, além de ser um dos métodos mais comumente utilizados, procura minimizar o número de variáveis fortemente relacionadas com cada fator, permitindo obter fatores mais facilmente interpretáveis. Pode-se expressar o modelo de análise fatorial algebricamente da seguinte forma:

$$
X_{i}=a_{i 1} F 1+a_{i 2} F 2+\cdots+a_{i j} F j+e_{i}
$$

em que $X_{i}$ representa o i-ésimo escore da variável padronizada, com média zero e variância unitária $(i=1,2, \ldots, m)$; $F j$ indica os fatores comuns não correlacionados, com média zero e variância unitária na j-ésima observação $(j=1,2, \ldots, n) ; a_{i j}$ representa as cargas fatoriais, e $e_{i}$, o termo de erro que capta a variação específica $X_{i}$ não explicada pela combinação linear das cargas fatoriais com os fatores comuns e imprecisões de medição de variáveis em função de erro de observação, de mensuração, e de especificação do modelo. 
De acordo com Johnson e Wichern (1992), as comunalidades das variáveis com explicação suficiente no modelo são aquelas maiores que 0,5 , variáveis com valores menores deverão ser retiradas. Por fim, o critério utilizado para definir 0 número de fatores foi 0 de considerar apenas aqueles que possuem raiz característica maior que um. Após o cálculo das cargas fatoriais e a identificação dos fatores comuns, torna-se necessário a estimação do escore fatorial, por meio do método semelhante ao de regressão. O escore para cada observação do modelo é, portanto, resultado da multiplicação do valor (padronizado) das variáveis pelo coeficiente do escore fatorial correspondente, sendo a expressão geral para estimação do j-ésimo fator.

Para testar a adequabilidade do modelo de análise fatorial, geralmente utilizase a estatística de Kaiser-Meyer-Olkin (KMO) e o Teste de Esfericidade de Bartlett (BTS) $)^{5}$ O $\mathrm{KMO}^{6}$ é um indicador que compara a magnitude do coeficiente de correlação observado com a magnitude do coeficiente de correlação parcial e o BTS serve para testar a hipótese nula de que a matriz de correlação é uma matriz identidade, se rejeitada a hipótese os dados são adequados e a análise fatorial poderá ser utilizada.

Extraídos os fatores e obtidos os scores destes, foi possível construir o IEPC e o GCE, explorados na subseção seguinte.

Índice de Estrutura Produtiva do Ceará (IEPC) e Grau de Crescimento Econômico (GCE)

Para a obtenção do IEPC foi necessário estimar um Índice Bruto de Estrutura Produtiva (IBEP). Conforme explica Morais, Sobreira e Lima (2018) ele é obtido através do cálculo da média dos fatores, ponderadas pela variância, pertencentes a cada microrregião. A ponderação pela proporção de explicação da variância total (dada pelo valor da raiz característica) exprime a importância relativa de cada fator. De acordo com Melo e Parré (2007), o IBEP pode ser expresso da seguinte forma:

$$
\text { IBEP }=\frac{\sum_{i=1}^{n}\left(w_{i} F_{i}\right)}{\sum_{i=1}^{n}\left(w_{i}\right)}
$$

\footnotetext{
${ }^{5}$ Bartlett's Test of Sphericity - BTS.

${ }^{6}$ Conforme grau de adequabilidade, utilizado por Missaggia (2012), é desejável que o valor do Índice KMO seja o mais próximo de 1 indicando perfeita adequação dos dados à Análise Fatorial.
} 
onde $w_{i}$ é a proporção da variância explicada por cada fator (raiz característica) e $F_{i}$ são os escores fatoriais. A partir do IBEP foi possível calcular o Índice de Estrutura Produtiva do Ceará. O IEPC foi construído a partir do método min-max, em que o maior valor adquire o valor cem e o menor zero, ou seja, a variação do índice ocorre no intervalo entre 0 e 1 , sendo os valores intermediários obtidos por interpolação (PEROBELLI et al., 1999). O Índice de Estrutura Produtiva do Ceará é dado por:

$$
I E P C_{q c}=\frac{x_{q c}-\min _{c}\left(x_{q}\right)}{\max _{c}\left(x_{q}\right)-\min _{c}\left(x_{q}\right)}
$$

onde $x_{q c}$ é o valor da observação $(q)$ do índice bruto para a microrregião $(c)$; $\min _{c}$ é o menor valor do índice bruto dentre todas as microrregiões; e $\max _{c}$ é o maior valor do índice bruto dentre todas as microrregiões estudadas.

A obtenção do IEPC possibilitou fazer uma ordenação das microrregiões do estado do Ceará. Baseando-se na classificação feita em Xerxenevsky e Fochezatto (2015) e Morais, Sobreira e Lima (2018), foram consideradas com grau de crescimento alto $(A)$, aquelas microrregiões que apresentaram resultados com um desvio-padrão acima da média; médio (M), aquelas com valores entre a média e um desvio-padrão acima da média; e por fim, baixo (B), as microrregiões com índice abaixo da média.

\section{Área de estudo e base de dados}

O recorte geográfico trata das trinta e três microrregiões do Ceará, onde se optou por estudar as suas estruturas produtivas. Os dados da pesquisa são de natureza secundária, provenientes de órgãos oficiais, tendo como principais fontes: Relação Anual de Informações Sociais (RAIS), disponível através do portal do Ministério do Trabalho e Emprego (MTE); Pesquisa Pecuária Municipal (PPM), Produção Agrícola Municipal (PAM) e Produção da Extração Vegetal e da Silvicultura (PEVS) do Instituto Brasileiro de Geografia e Estatística (IBGE); Ministério do Desenvolvimento Indústria e Comércio Exterior (MDIC). Conforme demonstra o Quadro 01.

Todas as variáveis são referentes aos anos de 2007 e 2017. O período de uma década a partir do início do Governo Cid Gomes em 2007, onde o estado do Ceará apresentou, nesse período, uma taxa de crescimento econômico média de 
$11,2 \%$, a terceira maior do Nordeste segundo dados do IBGE. A escolha do ano 2007 é caracterizado, nesta pesquisa, como ano base, onde a partir dele será possível fazer uma comparação com o ano final. Vale destacar que as 24 proxies utilizadas para análise fatorial são as mesmas para o período selecionado, fundamentando-se pelo interesse em explorar as principais mudanças no quadro produtivo das 33 microrregiões do estado.

No Quadro 01, estão descritas as 24 proxies utilizadas, em que foram indicadas nos trabalhos de Rezende, Fernandes e Silva (2007), Xerxenevsky e Fochezatto (2011), Lima e Maia (2015), Alves et al. (2018), Morais, Sobreira e Lima (2018) e que abordam temáticas sobre estrutura produtiva.

Quadro 01 - Descrições das variáveis utilizadas, Microrregiões do Ceará, 2007 e 2017

\begin{tabular}{|c|c|c|c|}
\hline Var & Descrição & Unid. & Fonte \\
\hline $\mathbf{X 0 1}$ & Importações & Mil $\mathrm{R} \$$ & MDIC \\
\hline $\mathbf{X 0 2}$ & Exportações & Mil $R \$$ & MDIC \\
\hline X03 & Trabalhadores formais de hotéis e similares & Qtd. & RAIS/MTE \\
\hline $\mathbf{X 0 4}$ & Trabalhadores formais vinculados ao setor da indústria & Qtd. & RAIS/MTE \\
\hline $\mathbf{X 0 5}$ & Trabalhadores formais vinculados ao setor da const. civil & Qtd. & RAIS/MTE \\
\hline X06 & Trabalhadores formais vinculados ao setor do comércio & Qtd. & RAIS/MTE \\
\hline $\mathbf{X 0 7}$ & Trabalhadores formais vinculados ao setor da serviços & Qtd. & RAIS/MTE \\
\hline $\mathbf{X 0 8}$ & Trabalhadores formais vinculados ao setor agropecuário & Qtd. & RAIS/MTE \\
\hline X09 & Estabelecimento de hotéis e similares & Qtd. & RAIS/MTE \\
\hline $\mathbf{X 1 0}$ & Estabelecimentos do setor industrial & Qtd. & RAIS/MTE \\
\hline $\mathbf{X 1 1}$ & Estabelecimentos do setor da construção civil & Qtd. & RAIS/MTE \\
\hline $\mathbf{X 1 2}$ & Estabelecimentos do setor do comércio & Qtd. & RAIS/MTE \\
\hline $\mathbf{X 1 3}$ & Estabelecimentos do setor de serviços & Qtd. & RAIS/MTE \\
\hline $\mathbf{X 1 4}$ & Estabelecimentos do setor agropecuário & Qtd. & RAIS/MTE \\
\hline $\mathbf{X 1 5}$ & Área plantada ou destinada à colheita das lavouras & Hectares & PAM/IBGE \\
\hline $\mathbf{X 1 6}$ & Área colhida & Hectares & PAM/IBGE \\
\hline $\mathbf{X 1 7}$ & Valor da produção* das lavouras & Mil $\mathrm{R} \$$ & PAM/IBGE \\
\hline $\mathbf{X 1 8}$ & Valor da produção* na extração vegetal & Mil $\mathrm{R} \$$ & PEVS/IBGE \\
\hline $\mathbf{X 1 9}$ & Produto Interno Bruto* & Mil $R \$$ & IBGE \\
\hline $\mathbf{X 2 0}$ & Valor adicionado bruto* - agropecuário & Mil $R \$$ & IBGE \\
\hline $\mathbf{X 2 1}$ & Valor adicionado bruto* - indústria & Mil $\mathrm{R} \$$ & IBGE \\
\hline $\mathbf{X 2 2}$ & Valor adicionado bruto* - serviços ${ }^{* *}$ & Mil R\$ & IBGE \\
\hline $\mathbf{X 2 3}$ & Produção de origem animal & Mil $\mathrm{R} \$$ & PPM/IBGE \\
\hline $\mathbf{X 2 4}$ & Efetivo dos rebanhos & Qtd. & PPM/IBGE \\
\hline
\end{tabular}

Fonte: Elaboração própria dos autores. * Todos os valores de produção são valores nominais a preços correntes. ${ }^{* *}$ Inclusive serviços de administração, defesa, educação e saúde públicas e seguridade social.

As variáveis X01 e X02 apresentam os dois elementos fundantes importação e exportação, essenciais para compreensão da Balança Comercial do estado e da própria inserção das microrregiões no mercado internacional. As variáveis X3 a X14 
apresentam as características do mercado de trabalho formal, como trabalhadores formais e estabelecimentos dos cinco grandes setores da economia. Ressalta-se que as proxies para turismo (X03 e X09) foram subtraídas das variáveis de serviço. O objetivo foi destacar a dinâmica de serviços de turismo no estado (ALVES et al., 2018).

As variáveis $\mathrm{X} 15$ a $\mathrm{X} 18$ apresentam características referentes à área de plantio e ao valor dessas produções. Seguido pelas variáveis X19 a X22 que apresentam o PIB, VAB agropecuário, indústria e de serviços das microrregiões. Por fim, foram incluídos elementos da pecuária cearense (X23 e X24), que conforme explorado anteriormente, representam um relevante eixo econômico histórico do estado, conforme ressaltado por Lima Júnior $(2014)^{7}$.

Os softwares utilizados foram o IBM SPSS Statistics 20 e o QGIS 3.0.3. A seção seguinte explora os resultados obtidos para o ano de 2007 e para o ano 2017, onde são tecidas algumas comparações relevantes entre as características que mudaram ao longo do tempo de análise.

\section{Resultados e Discussão}

Nesta seção, são apresentados os principais resultados obtidos com a Análise Fatorial (AF), bem como o ranking das microrregiões e o exercício da espacialidade referente ao estudo da estrutura produtiva no comparativo 2007 e 2017. O tópico 5.1 aborda os resultados da Análise Fatorial, para os anos em estudo, bem como foi apresentado o IEPC. Nessa perspectiva, o tópico 5.2 identifica e categoriza o Grau de Crescimento Econômico (GCE) das microrregiões em alto (A), médio (M) e baixo (B). Em seguida é feita uma análise espacial. Vale ressaltar, que de acordo com Lima e Maia (2015) ao incluir outros recortes temporais a análise da AF se torna mais robusta e completa, além de ser mais precisa nos resultados constatados.

\section{Extração de Fatores da Estrutura produtiva}

Fatores interdependentes para o ano de 2007

A análise aplicada para as 24 variáveis apresentou no ano de 2007 quatro fatores com raiz característica maior que uma unidade. Cada fator engloba as

\footnotetext{
$7 \mathrm{O}$ autor resgata o tripé indústria incentivada-agronegócio-turismo como determinante das políticas de estímulo ao desenvolvimento cearense. As variáveis aqui descritas e utilizadas representam bem os segmentos deste tripé.
} 
variáveis que apresentam um padrão parecido e, dessa forma, com os dados utilizados quatro fatores explicam o dinamismo da estrutura produtiva. Após a rotação com o método Varimax, conclui-se que os fatores selecionados explicam um total de $96,4 \%$ da variabilidade total das variáveis selecionadas. Sendo que, individualmente: o Fator 1 (F1) explica a maior variância, com 65,76\%; o Fator 2 (F2) explica 11,41\%; o Fator 3 (F3) explica 11,29\%; e o Fator 4 (F4) explica um total de $7,96 \%$.

No método de componentes principais, o teste para mostrar o quanto os fatores explicam a variância total dos dados é o Kaiser-Meyer-Olkin (KMO), que apresentou um índice igual a 0,761, situando-se em um intervalo bom, possibilitando e indicando o uso da técnica de análise fatorial (PEROBELLI et al., 1999; MISSAGGIA, 2012; MORAIS; SOBREIRA; LIMA, 2018).

Na realização de um segundo teste, o Bartlett's Test of Sphericity, verificou-se que é improvável a matriz de correlação ser uma identidade. Isto é representado por um alto índice gerado pelo teste BTS $(3204,209)$ e um nível de significância igual a zero, rejeitando-se a hipótese nula de que a matriz de correlação é uma matriz identidade, indicando que os dados utilizados são adequados. Após a rotação pelo método Varimax e obtenção de resultados a Tabela 01 apresenta o conjunto de cargas fatoriais ${ }^{8}$ e as comunalidades para os indicadores considerados e seus respectivos fatores.

Fator 1 (F1), representa $65,76 \%$ da variância total das variáveis que estão positivamente correlacionadas com este fator, podendo este ser identificado como inerente às características da estrutura da relação de trabalhadores formais e estabelecimentos nos setores da economia (X03 ao X14) sendo que X03 e X09 representam o subsetor de hotéis e similares. As transações internacionais são aqui demonstradas através da balança comercial das microrregiões cearenses: importações (X01) e exportações (X02) com correlações de 0,978 e 0,924, respectivamente, nesse período o Ceará apresentava um saldo de Balança Comercial deficitário de US\$200,7 milhões, conforme aponta dados da SECEX/MDIC.

Além da relação de empregos e a balança comercial, o F1 apresenta alta correção $(0,983)$ com o VAB de serviços, assim como a variável PIB a preços correntes (X19), com correlação de 0,981 . Outras variáveis como Valor Adicionado

\footnotetext{
${ }^{8}$ Cargas fatoriais, conforme indicado por Haddad et al. (1989), organizadas em nível decrescente e em negrito, para melhor visualizar cada fator considerado.
} 
Bruto da Indústria (X21), apresenta carga fatorial de 0,978. Assim, o Fator 1 é aqui denominado como Indicador de Estrutura Econômica.

Tabela 01 - Cargas Fatoriais e Comunalidade após a rotação pelo método Varimax - 2007*

\begin{tabular}{|c|c|c|c|c|c|}
\hline \multirow{2}{*}{ Indicadores } & \multicolumn{4}{|c|}{ Cargas Fatoriais } & \multirow{2}{*}{ Comunalidade } \\
\hline & F1 & F2 & F3 & F4 & \\
\hline X07 & 0,985 & $-0,021$ & 0,078 & 0,142 & 0,996 \\
\hline $\mathrm{X} 13$ & 0,984 & $-0,052$ & 0,073 & 0,141 & 0,997 \\
\hline X03 & 0,983 & $-0,016$ & 0,067 & 0,155 & 0,994 \\
\hline X22 & 0,983 & $-0,023$ & 0,087 & 0,149 & 0,997 \\
\hline X06 & 0,983 & $-0,049$ & 0,08 & 0,145 & 0,996 \\
\hline $\mathrm{X} 11$ & 0,983 & $-0,053$ & 0,064 & 0,153 & 0,997 \\
\hline$\times 19$ & 0,981 & $-0,026$ & 0,096 & 0,158 & 0,997 \\
\hline$\times 10$ & 0,981 & $-0,049$ & 0,102 & 0,145 & 0,995 \\
\hline X05 & 0,979 & $-0,06$ & 0,112 & 0,144 & 0,995 \\
\hline X09 & 0,978 & 0,079 & 0,074 & 0,139 & 0,988 \\
\hline $\mathrm{X} 12$ & 0,978 & $-0,027$ & 0,102 & 0,153 & 0,991 \\
\hline$X 21$ & 0,978 & $-0,038$ & 0,086 & 0,17 & 0,994 \\
\hline X01 & 0,978 & $-0,076$ & 0,066 & 0,157 & 0,992 \\
\hline X04 & 0,971 & $-0,033$ & 0,09 & 0,174 & 0,982 \\
\hline X02 & 0,924 & 0,07 & 0,113 & 0,259 & 0,939 \\
\hline$\times 14$ & 0,872 & 0,144 & 0,361 & 0,203 & 0,953 \\
\hline $\mathrm{X} 16$ & $-0,08$ & 0,956 & 0,142 & 0,141 & 0,961 \\
\hline$\times 15$ & $-0,084$ & 0,954 & 0,139 & 0,163 & 0,963 \\
\hline$\times 18$ & 0,028 & 0,792 & 0,283 & $-0,224$ & 0,759 \\
\hline $\mathrm{X} 17$ & $-0,069$ & 0,218 & 0,951 & $-0,002$ & 0,957 \\
\hline$\times 20$ & 0,127 & 0,399 & 0,823 & 0,249 & 0,915 \\
\hline$\times 08$ & 0,478 & 0,093 & 0,787 & 0,129 & 0,873 \\
\hline X24 & 0,5 & 0,082 & 0,07 & 0,842 & 0,971 \\
\hline X23 & 0,447 & 0,091 & 0,372 & 0,769 & 0,938 \\
\hline $\begin{array}{c}\text { Variância } \\
\text { Explicada } \\
\text { pelo Fator (\%) }\end{array}$ & 65,764 & 11,416 & 11,289 & 7,956 & - \\
\hline
\end{tabular}

Fonte: Elaboração própria a partir dos resultados.

* Matriz de componente rotativa (Rotação convergida em 6 iterações); * Método de Extração: Análise de Componente Principal; * Método de Rotação: Varimax com Normalização de Kaiser.

O Fator 2 (F2), com um total de $11,4 \%$ de explicação da variância total das variáveis representa o Indicador de Áreas de Plantio, onde as variáveis X15 referente à área plantada ou destinada à colheita das lavouras temporárias e permanentes, X16 refere-se à área colhida e valor de produção na extração vegetal representado aqui pela variável X17. Essas variáveis são altamente correlacionadas com este fator, isso representa que os grandes cultivos de áreas destinadas à colheita, representam um fator importante e relevante na estrutura produtiva do estado. Resultados similares foram encontrados por Alves et al. (2018), evidenciando que tais dados são mais voltados a área geográfica e não a valores econômicos. Muito embora com correlação de 0,792 a variável X17, também apresentou uma correlação elevada para com o Fator 3 de 0,283. São pequenas 
características das microrregiões que ajustam a correção dos fatores, nesse caso a variável em questão foi mais altamente correlacionada com o Indicador de Estrutura de Lavouras, algo comum a ser encontrado na literatura (ALVES et al., 2018; MORAIS; SOBREIRA; LIMA, 2018).

Para o Fator 3 (cujo percentual da variância explicada foi de 11,3\%) apresentou características intrínsecas ao setor agrícola. As variáveis X17 com 0,951 e X20 com 0,823, são as variáveis mais altamente correlacionadas com o Fator, indicando o valor da produção das lavouras temporárias e permanentes e o VAB Agropecuário, já a variável X08, referente ao número de trabalhadores formais vinculados ao setor agropecuário, apresentou correlação de 0,787. Apresentando os aspectos mais relevantes da Estrutura Agrícola. Logo, F3 está medindo a intensidade da participação do setor primário no que diz respeito à produção das microrregiões, tanto de longo quanto de curto prazo. Sendo assim, denomina-se Indicador da Estrutura Agrícola.

Por fim, o Fator 4, explica o percentual mais baixo, totalizando 7,96\% da variância total das variáveis, e expressa a produção de origem animal e o efetivo dos rebanhos, ambos por tipo (X24 e X23, respectivamente). Nesse ínterim, é interessante destacar que essas variáveis "descolaram-se" do Fator 3, por ser uma medida com dados mais específicos e de maior importância bruta das microrregiões voltado à pecuária. $E$, deste modo, não teve uma correlação forte o suficiente para integrar a este fator, mesmo apresentando uma alta correlação com o F1 de 0,447 e F3 de 0,372 no caso da variável X24, em vista de que algumas áreas do estado são propícias à pecuária e não à agricultura. No entanto, o Fator 4 é aqui denominado Indicador da Estrutura Pecuária.

\section{Fatores interdependentes para o ano de 2017}

Foram quatro os fatores obtidos no ano de 2017, com raiz característica maior que uma unidade. Após a rotação com o método Varimax, concluiu-se que os fatores selecionados explicam um total de $92,71 \%$ da variabilidade total das variáveis selecionadas para a amostra. Sendo que destes o Fator 1 é responsável por $64,58 \%$ da variância total, o Fator 2 detém de 15,03\%, o Fator 3 um total de $7,08 \%$ e o Fator 4 com $6,02 \%$.

Verificando a adequação dos dados obtidos após a análise fatorial, no método de componentes principais, tem-se que o KMO apresenta um índice igual a 0,709, situando-se em um intervalo bom, possibilitando e indicando o uso da análise fatorial 
para os dados selecionados. Já o Bartlett's Test of Sphericity, verificou-se que é improvável a matriz de correlação ser uma identidade. Pois apresenta um índice alto de 3.176,311 e um nível de significância igual a zero, indicando que os dados utilizados são adequados e a técnica de análise fatorial poderá ser utilizada. A rotação pelo método Varimax e obtenção de resultados, a Tabela 02 apresenta 0 conjunto de cargas fatoriais ${ }^{9}$ e as comunalidades para os indicadores considerados e seus respectivos fatores.

O F1 representa $64,58 \%$ da variância total das variáveis que estão positivamente correlacionadas com esse fator, podendo identificar com as características de trabalho, mantendo a relação de trabalhadores formais e estabelecimentos (X03 a X07; X09 a X13). Já que engloba todos os setores da economia e o subsetor de hotéis e similares, exceto o número de trabalhadores e estabelecimentos do setor agropecuário, isso se deve ao fato dessas variáveis serem mais correlacionadas com outro fator observado (Fator 2). Destarte, o F1 explica as atividades econômicas de exportações (X23) e importações (X24), com correlações de 0,674 e 0,671, respectivamente. Segundo o IPECE (2017) desde 2007, o melhor saldo da balança comercial estadual foi registrado em 2017, com um déficit de US\$138,69 milhões. Vale ressaltar que esse valor é reflexo do cenário econômico que o Ceará vinha apresentando nesses últimos anos, com a consolidação do Complexo Industrial e Portuário do Pecém (CIPP), que na sua consolidação demandou intensas importações de insumos industriais expressas em outras variáveis explicadas por este fator, como o Produto Interno Bruto a preços correntes (X19), Valor Adicionado Bruto da indústria (X21) e Valor Adicionado Bruto de serviços (X22). Nesse sentido, o Fator 1 é aqui denominado como Indicador de Estrutura Econômica.

Para F2, cujo percentual da variância explicada foi de 15,03\%, verificou-se uma forte e positiva correlação com as variáveis X08, X14, X17 e X20. Apresentando os aspectos mais relevantes da Estrutura Agrícola, como trabalhadores por vínculo no grande setor de Agropecuária (X08), número de estabelecimentos do setor agropecuário (X14) e valor da produção das lavouras temporárias e permanentes (X17) e VAB a preços correntes da agropecuária (X20). Denomina-se aqui como Indicador de Estrutura Agrícola.

${ }^{9}$ Conforme indicado por Haddad et al. (1989), organizadas em nível decrescente e em negrito, como foi organizado na análise anterior. 
Tabela 02 - Cargas Fatoriais e Comunalidade após a rotação pelo método Varimax - 2017*

\begin{tabular}{|c|c|c|c|c|c|}
\hline \multirow{2}{*}{ Indicadores } & \multicolumn{4}{|c|}{ Cargas Fatoriais } & \multirow{2}{*}{ Comunalidade } \\
\hline & F1 & F2 & F3 & F4 & \\
\hline X07 & 0,979 & 0,177 & $-0,054$ & 0,061 & 0,996 \\
\hline X13 & 0,978 & 0,175 & $-0,065$ & 0,069 & 0,997 \\
\hline $\mathrm{X} 22$ & 0,977 & 0,183 & $-0,042$ & 0,082 & 0,996 \\
\hline X06 & 0,977 & 0,172 & $-0,069$ & 0,083 & 0,996 \\
\hline $\mathrm{X} 10$ & 0,976 & 0,178 & $-0,069$ & 0,095 & 0,997 \\
\hline X05 & 0,975 & 0,196 & $-0,07$ & 0,041 & 0,996 \\
\hline X11 & 0,975 & 0,185 & $-0,065$ & 0,08 & 0,996 \\
\hline X12 & 0,974 & 0,172 & $-0,047$ & 0,113 & 0,994 \\
\hline X19 & 0,973 & 0,204 & $-0,043$ & 0,085 & 0,997 \\
\hline X03 & 0,970 & 0,182 & 0,087 & 0,086 & 0,988 \\
\hline X04 & 0,964 & 0,214 & $-0,061$ & 0,07 & 0,983 \\
\hline X21 & 0,953 & 0,288 & $-0,041$ & 0,047 & 0,994 \\
\hline X09 & 0,910 & 0,202 & 0,249 & 0,157 & 0,955 \\
\hline X01 & 0,674 & 0,284 & 0,006 & 0,539 & 0,825 \\
\hline X02 & 0,671 & 0,261 & 0,238 & 0,563 & 0,891 \\
\hline X20 & 0,161 & 0,855 & 0,072 & $-0,162$ & 0,788 \\
\hline X14 & 0,377 & 0,742 & $-0,052$ & 0,288 & 0,778 \\
\hline X08 & 0,388 & 0,686 & $-0,07$ & 0,417 & 0,8 \\
\hline$X 17$ & 0,656 & 0,671 & $-0,082$ & $-0,088$ & 0,895 \\
\hline X15 & $-0,075$ & 0,012 & 0,935 & 0,216 & 0,927 \\
\hline X16 & $-0,075$ & 0,012 & 0,935 & 0,216 & 0,927 \\
\hline X18 & 0,021 & $-0,049$ & 0,900 & 0,052 & 0,816 \\
\hline X24 & 0,125 & 0,09 & 0,214 & 0,924 & 0,924 \\
\hline X23 & $-0,038$ & $-0,076$ & 0,245 & 0,851 & 0,792 \\
\hline $\begin{array}{c}\text { Variância } \\
\text { Explicada pelo } \\
\text { Fator (\%) }\end{array}$ & 64,58 & 15,03 & 7,08 & 6,02 & - \\
\hline
\end{tabular}

Fonte: Elaboração própria a partir dos resultados.

* Matriz de componente rotativa (Rotação convergida em 5 interações); * Método de Extração: Análise de Componente Principal; * Método de Rotação: Varimax com Normalização de Kaiser.

O Fator 3 explica $7,08 \%$ da variância total das variáveis, expressa 0 crescimento e a importância das áreas de plantio. Portanto, é aqui denominado Indicador de Áreas de Plantio das microrregiões. As variáveis potencialmente correlacionadas com esse fator são X15 (área plantada ou destinada à colheita das lavouras temporárias e permanentes), X16 (área colhida) e X18 (valor da produção na extração vegetal) com respectivos $0,935,0,935$ e 0,900 coeficientes de correlação.

Por fim, representando um total de 6,02\% da explicação da variância total, está o Fator 4 (F4). Onde as variáveis produção de origem animal, por tipo de produto em valor da produção (X23) e efetivo dos rebanhos, por tipo (X24) apresentam forte correlação com este Fator 4 (0,924 e 0,851, respectivamente). Nesse ínterim, é interessante destacar que assim como o F4 da análise anterior, essas variáveis "descolaram-se" do Fator 2 - Indicador da Estrutura Agrícola, por se tratar de um dado voltado à área geográfica e plantio, mas não a valores ou medidas 
com dados mais específicos à produção agrícola. Esse indicador não teve uma correlação forte e nem mesmo uma carga fatorial que identificasse essas variáveis ao Fator 2. Denomina-se assim Indicador de Estrutura Pecuária.

\section{Grau de Crescimento Econômico das Microrregiões do Ceará}

Após a verificação das cargas fatoriais, foram calculados os escores fatoriais para cada microrregião que por sua vez foram utilizados para construir uma ordenação das microrregiões estudadas, conforme o potencial de sua estrutura produtiva. Perobelli et al. (1999) destacam que a posição ocupada pela microrregião através da tipologia construída refere-se à posição relativa dentro da região analisada, de forma intra estadual.

Por meio da construção do IEPC, foi possível categorizar o Grau de Crescimento Econômico (GCE) da estrutura produtiva em: alto, médio e baixo. Em uma escala de 0 a 100, o Índice de Estrutura Produtiva do Ceará (IEPC) médio para o ano de 2007 foi de 7,7 com um desvio padrão de 17,01, já em 2017 a média do IEPC foi de 8,7 e o desvio padrão de 17,08, havendo assim um considerado aumento no que diz respeito à média do índice repercutindo diretamente no desenvolvimento das atividades produtivas nas microrregiões do estado. Identificase também um aumento na dispersão dessas atividades produtivas mesmo que se tenha interiorizado e se espraiado pelo território cearense.

Grau de desenvolvimento das microrregiões no ano de 2007

Conforme a metodologia também utilizada nos trabalhos de Perobelli et al. (1999) e Morais, Sobreira e Lima (2018), em relação às microrregiões classificadas com alto GCE, uma delas foi classificada nesse grupo, o que representa apenas $3 \%$ das microrregiões do estado. Outros $12,1 \%$ das microrregiões do Ceará apresentavam, nesse período, um GCE da estrutura produtiva médio. Por fim, $84,8 \%$ de todas às microrregiões foram classificadas com baixo grau de crescimento econômico, isto é, 28 microrregiões.

No contexto de sua economia, no Ceará, durante o ano de 2007, prevalecia um baixo grau de desenvolvimento das estruturas produtivas, o que pode estar associado, em parte, ao baixo nível de desenvolvimento regional, devido aos desajustes regionais que prevaleceram durante boa parte do século $X X$ e sua exponenciação face às medidas de desregulamentação e de abertura da economia 
prevalecentes na última década deste século (MORAIS, MACEDO, LIMA JÚNIOR, 2014).

Tal quadro foi marcado, como observado em outros indicadores que mensuram o desenvolvimento e também a forte concentração em termos de população e de atividades dinâmicas na economia do Ceará na região litorânea, conforme destaca Alves et al. (2017). Outro ponto importante a destacar é sobre o forte processo de reestruturação produtiva, já que por concentrar as atividades mais dinâmicas na região litorânea o processo de flexibilização da cadeia produtiva acontece com maior nitidez, se adequando aos novos moldes do capitalismo. Havendo também forte concentração populacional.

A análise dos escores fatoriais por nível de estrutura produtiva pode ser observado na Tabela 03. Ressalta-se que para a análise dos fatores, os escores fatoriais são variáveis com média zero e desvio padrão igual a 1, sendo os escores próximos a zero um indicativo de média estrutura produtiva, conforme os estudos de Morais, Sobreira e Lima (2018).

Deste modo, quanto maior o valor do fator em relação a zero, mais produtiva é a determinada estrutura das microrregiões. Uma situação de relativo atraso manifesta-se através de valores negativos dos fatores. Para Hoffman (1992) os fatores com valores maiores do que uma unidade indica que as microrregiões são intensivas naquele fator.

Nessa perspectiva, por meio da média e desvio padrão referente a cada GCE das observações, pode-se fazer inferências no que diz respeito à intensidade do crescimento das microrregiões em relação a cada fator.

Tabela 03 - Média e desvio-padrão dos fatores de acordo com o GCE - 2007

\begin{tabular}{|c|c|c|c|}
\hline GCE & Fator & Média & Desvio-Padrão \\
\hline \multirow{4}{*}{ Alto } & F1 & 5,4680 & 0,0000 \\
\hline & F2 & $-0,4114$ & 0,0000 \\
\hline & F3 & 0,3169 & 0,0000 \\
\hline & F4 & 0,7538 & 0,0000 \\
\hline \multirow{4}{*}{ Médio } & F1 & 0,1049 & 0,2614 \\
\hline & F2 & 1,4921 & 1,4568 \\
\hline & F3 & 0,9820 & 2,0014 \\
\hline & F4 & $-0,4460$ & 0,3997 \\
\hline \multirow{4}{*}{ Baixo } & F1 & $-0,2103$ & 0,1395 \\
\hline & F2 & $-0,1985$ & 0,6901 \\
\hline & F3 & $-0,1516$ & 0,6374 \\
\hline & F4 & 0,0368 & 1,0344 \\
\hline
\end{tabular}

Fonte: Elaboração própria a partir dos resultados. 
Em linhas gerais, é possível identificar que as microrregiões que apresentam alto GCE são mais intensivas no Indicador de Estrutura Econômica (F1), este por apresentar maior grau de explicação da variância total das variáveis também é o que responde pelo alto GCE das microrregiões, com média de 5,4680, ou seja, apenas a microrregião de Fortaleza, nesse período. Seguido pelo F4, que é o Indicador de Estrutura Pecuária, pode-se considerar em virtude das variáveis valor da produção de origem animal e efetivo dos rebanhos, que apresentam alto grau de correlação com este fator, deslocam-se para regiões facilitadoras da comercialização, apresentando grande importância histórica/econômica da pecuária na economia cearense.

No que tange às microrregiões classificadas com médio GCE, estas apresentam valores médios do F1 próximos de zero, indicando que possuem intensidade mediana ou intermediária no Indicador de Estrutura Econômica e apresentam relativos avanços ${ }^{10} \mathrm{em}$ outros dois fatores analisados F2 e F3 1,4921 e 0,9820 , respectivamente.

Já nas microrregiões classificadas de estrutura produtiva de menor crescimento econômico ou mais atrasada, observa-se que o F1 apresenta o pior resultado para essas microrregiões com a média para este fator sendo igual a 0,2103 , seguido pelo F3 $(-0,1985)$ e F2 $(-0,1516)$. Apenas o F4 apresenta valor médio acima de zero, de 0,0368.

\section{Grau de desenvolvimento das microrregiões no ano de 2017}

O cenário das estruturas produtivas do Ceará em 2017, já apresenta alterações do quadro anterior visto 2007. No ano de 2017, houve um aumento para quatro no número de microrregiões com alto GCE, equivalendo a $12,1 \%$ das microrregiões. Em relação aquelas classificadas com médio GCE representam um percentual de $18,2 \%$. Por fim, $69,7 \%$ de todas às microrregiões foram classificadas com baixo GCE, isto é, 20 microrregiões. Em termos gerais, durante os dois momentos do corte de análise, prevalecem um baixo grau de crescimento econômico das estruturas produtivas, entretanto o processo de interiorização e desconcentração repercutiram positivamente no setor produtivo do estado, havendo desenvolvimento e redução das disparidades intraestaduais.

A análise dos escores fatoriais por nível de estrutura produtiva no ano de 2017 pode ser observado por meio da Tabela 04. Nessa perspectiva, é possível

10 Por apresentarem valores negativos assim como afirma Hoffman (1992). 
identificar que as microrregiões que apresentam alto GCE são mais intensivas no Indicador de Estrutura Econômica, por apresentar maior grau de explicação da variância total das variáveis também é o que melhor representa o alto GCE das microrregiões, com média de 1,4992 . Segue-se o F2 $(1,1378)$ que representa 0 Indicador de Estrutura Agrícola e pelo Fator 3, que é o Indicador de Área de Plantio, que continuam, assim como 2007, a apresentar alto grau de correlação e importância econômica.

Tabela 04 - Média e desvio-padrão dos fatores de acordo com o GCE - 2017

\begin{tabular}{|c|c|c|c|}
\hline GCE & Fator & Média & Desvio-Padrão \\
\hline \multirow{4}{*}{ Alto } & F1 & 1,4992 & 2,3084 \\
\hline & F2 & 1,1378 & 2,0082 \\
\hline & F3 & 0,2441 & 0,7354 \\
\hline & F4 & 0,1742 & 0,4047 \\
\hline \multirow{4}{*}{ Médio } & F1 & $-0,1308$ & 0,0559 \\
\hline & F2 & 0,5828 & 0,5757 \\
\hline & F3 & 0,5293 & 1,2864 \\
\hline & F4 & $-0,1823$ & 0,1126 \\
\hline \multirow{4}{*}{ Baixo } & F1 & $-0,2266$ & 0,1305 \\
\hline & F2 & $-0,3499$ & 0,4091 \\
\hline & F3 & $-0,1805$ & 0,8657 \\
\hline & F4 & 0,0173 & 1,1599 \\
\hline
\end{tabular}

Fonte: Elaboração própria a partir dos resultados.

No que se referem às microrregiões classificadas com médio GCE, estas apresentaram valores intermediários do F2 e F3, ou seja, próximos de zero, porém positivos, indicando que essas microrregiões possuem intensidade média no Indicador de Estrutura Agrícola e Áreas de Plantio e, relativos atrasos nos outros dois fatores analisados F1 e F4 (-0,1308 e -0,1823, respectivamente).

Já as microrregiões classificadas com baixo GCE, os valores negativos dos fatores indicam o atraso relativo que essas regiões têm em sua estrutura produtiva. Os resultados menos expressivos para essas microrregiões foram o F2 e F1, com médias de -0,3499 e -0,2266, respectivamente. Na seção seguinte além de estabelecer o ranking das microrregiões, foi feito o exercício espacial por meio do IEPC.

\section{Espacialidade e Ranking das microrregiões do Ceará através do IEPC}

A dinâmica econômica brasileira dos anos 2000 em diante tem permitido ao mercado de trabalho elevado índice de contratações, em âmbitos formais, em todos os setores de atividade econômica. A partir dos resultados obtidos observou-se que no Ceará em 2007, somente uma microrregião com alto grau de estrutura produtiva 
foi verificada, sendo ela Fortaleza. Este desempenho se deve ao F1, que explica justamente os empregos formais e a quantidade de estabelecimentos nos setores produtivos do estado, devido aos altos índices de correlação das variáveis com este fator, mas também dos valores do PIB e Balança Comercial. Assim como o F2, que explica a estrutura agrícola e compõe um núcleo forte de produtividade situado nessa microrregião devido ao conjunto de segmentos primários que não necessariamente a agricultura.

Ocorre que em 2017 esse número quadruplica e, devido ao forte crescimento econômico das microrregiões de Litoral de Camocim e Acaraú, Sobral e Cariri, agora são quatro microrregiões com alto GCE. Em relação às microrregiões com médio GCE, observou-se que subiu de quatro para seis, microrregiões. O destaque é que passa a haver uma maior participação das microrregiões interioranas nos setores dinâmicos da econômica cearense.

No que se refere às microrregiões com médio GCE, cerca de 50\%, estão na mesorregião Noroeste Cearense em 2007 e em 2017 estão localizadas nas mesorregiões dos Sertões, Jaguaribe e Norte Cearense. Porém, ainda prevalece um baixo GCE da estrutura produtiva para a maioria das microrregiões do estado, conforme demonstrado no Quadro 02.

Quadro 02 - Ranking das microrregiões do Ceará segundo seu IEPC - 2007 e 2017

\begin{tabular}{|l|ccc|ccc|}
\hline \multirow{2}{*}{ Microrregiões } & \multicolumn{3}{|c|}{$\mathbf{2 0 0 7}$} & \multicolumn{3}{c|}{$\mathbf{2 0 1 7}$} \\
\cline { 2 - 7 } & IEPC & Ranking & GCE & IEPC & Ranking & GCE \\
\hline Fortaleza & 100,0 & 1 & $\mathrm{~A}$ & 100,0 & 1 & $\mathrm{~A}$ \\
\hline Litoral de C. e Acaraú & 21,5 & 2 & $\mathrm{M}$ & 30,2 & 2 & $\mathrm{~A}$ \\
\hline Sobral & 13,4 & 4 & $\mathrm{M}$ & 13,4 & 3 & $\mathrm{~A}$ \\
\hline Cariri & 12,0 & 5 & $\mathrm{M}$ & 12,1 & 4 & $\mathrm{~A}$ \\
\hline Sertão de Crateús & 7,0 & 7 & $\mathrm{~B}$ & 11,4 & 5 & $\mathrm{M}$ \\
\hline Baixo Jaguaribe & 15,6 & 3 & $\mathrm{M}$ & 10,3 & 6 & $\mathrm{M}$ \\
\hline Itapipoca & 7,6 & 6 & $\mathrm{~B}$ & 10,1 & 7 & $\mathrm{M}$ \\
\hline Sertão de S. Pompeu & 6,0 & 11 & $\mathrm{~B}$ & 8,7 & 8 & $\mathrm{M}$ \\
\hline Sertão de Quixeramobim & 4,3 & 15 & $\mathrm{~B}$ & 8,7 & 9 & $\mathrm{M}$ \\
\hline Litoral de Aracati & 6,5 & 9 & $\mathrm{~B}$ & 7,5 & 10 & $\mathrm{M}$ \\
\hline Sertão de Inhamuns & 4,7 & 14 & $\mathrm{~B}$ & 7,3 & 11 & $\mathrm{~B}$ \\
\hline Cascavel & 6,4 & 10 & $\mathrm{~B}$ & 6,6 & 12 & $\mathrm{~B}$ \\
\hline Canindé & 5,6 & 12 & $\mathrm{~B}$ & 6,3 & 13 & $\mathrm{~B}$ \\
\hline Ibiapaba & 6,8 & 8 & $\mathrm{~B}$ & 5,8 & 14 & $\mathrm{~B}$ \\
\hline Baturité & 5,4 & 13 & $\mathrm{~B}$ & 5,5 & 15 & $\mathrm{~B}$ \\
\hline Santa Quitéria & 2,5 & 20 & $\mathrm{~B}$ & 5,4 & 16 & $\mathrm{~B}$ \\
\hline Iguatu & 4,0 & 16 & $\mathrm{~B}$ & 4,3 & 17 & $\mathrm{~B}$ \\
\hline Chorozinho & 2,8 & 18 & $\mathrm{~B}$ & 4,0 & 18 & $\mathrm{~B}$ \\
\hline Chapada do Araripe & 2,3 & 22 & $\mathrm{~B}$ & 3,5 & 19 & $\mathrm{~B}$ \\
\hline Pacajus & 1,1 & 26 & $\mathrm{~B}$ & 3,3 & 20 & $\mathrm{~B}$ \\
\hline
\end{tabular}




\begin{tabular}{|l|lll|lll|}
\hline Coreaú & 2,2 & 24 & $\mathrm{~B}$ & 3,1 & 21 & $\mathrm{~B}$ \\
\hline Ipu & 3,2 & 17 & $\mathrm{~B}$ & 2,8 & 22 & $\mathrm{~B}$ \\
\hline Médio Curu & 0,6 & 28 & $\mathrm{~B}$ & 2,6 & 23 & $\mathrm{~B}$ \\
\hline Uruburetama & 2,4 & 21 & $\mathrm{~B}$ & 2,4 & 24 & $\mathrm{~B}$ \\
\hline Baixo Curu & 2,2 & 23 & $\mathrm{~B}$ & 2,2 & 25 & $\mathrm{~B}$ \\
\hline Várzea Alegre & 1,0 & 27 & $\mathrm{~B}$ & 2,2 & 26 & $\mathrm{~B}$ \\
\hline Barro & 2,7 & 19 & $\mathrm{~B}$ & 2,0 & 27 & $\mathrm{~B}$ \\
\hline Brejo Santo & 1,7 & 25 & $\mathrm{~B}$ & 2,0 & 28 & $\mathrm{~B}$ \\
\hline Serra do Pereiro & 0,0 & 33 & $\mathrm{~B}$ & 1,0 & 29 & $\mathrm{~B}$ \\
\hline Médio Jaguaribe & 0,2 & 31 & $\mathrm{~B}$ & 0,9 & 30 & $\mathrm{~B}$ \\
\hline Lavras da Mangabeira & 0,5 & 30 & $\mathrm{~B}$ & 0,8 & 31 & $\mathrm{~B}$ \\
\hline Caririaçu & 0,6 & 29 & $\mathrm{~B}$ & 0,7 & 32 & $\mathrm{~B}$ \\
\hline Meruoca & 0,0 & 32 & $\mathrm{~B}$ & 0,0 & 33 & $\mathrm{~B}$ \\
\hline
\end{tabular}

Fonte: Elaboração própria a partir dos resultados. *GCE - Grau de Crescimento Econômico.

As quatro microrregiões que dominam o maior índice em 2007, são os principais polos das atividades produtivas na atualidade, localizados no litoral: Fortaleza, Litoral de Camocim e Acaraú e, na sua proximidade, Sobral. Vale destacar o forte potencial no setor turístico da microrregião do Litoral de Camocim e Acaraú, onde se localiza um dos principais polos praianos que é complexo de Jijoca de Jericoacara. Contudo, Oliveira (2016) afirma que no Semiárido historicamente se concentrou uma economia de baixa produtividade, baseada na pecuária extensiva e na agricultura de subsistência e contando ainda com o agravante das secas cíclicas, o que de fato foi provado através do F2, F3 e F4 em que representam características que mais explica a formação da estrutura produtiva das microrregiões interioranas.

Outros destaques se dão pelas microrregiões do Baixo Jaguaribe, localizado no leste do estado, região de destaque pelos polos de fruticultura irrigada e grandes criatórios voltados à exportação de crustáceos e peixes. O polo regional localizado no Sul cearense, a microrregião do Cariri, tem como destaque as três cidades cornubadas e que conciliam mais de $50 \%$ do PIB da microrregião, Crato, Juazeiro do Norte e Barbalha - CRAJUBAR, onde se destaca a indústria calçadista, o setor de serviços e a construção civil.

De modo geral, a economia cearense está centrada na produção agrícola de grãos e frutos e por isso o destaque para o F2, referente ao Indicador de Áreas de Plantio. Além de ser considerado de grande importância o plantio de culturas de arroz, feijão, da cana-de-açúcar, coco, banana e melão.

Em 2017, houveram modificações pontuais. Tais modificações indicam tanto que houve melhorias em termos de estrutura produtiva em alguns casos, como 
Sertão de Crateús, Itapipoca, Sertão de Senador Pompeu, Sertão de Quixeramobim e Litoral de Aracati, passando a integrar o grupo classificados como médio GCE.

Vale destacar que também houve redução na importância econômica em outras microrregiões como Baixo Jaguaribe que caiu da $3^{\text {a }}$ colocação para a 6 $6^{\text {a }}$, e outras como Ipu, Ibiapaba e Barro que apresentaram, em 2017, uma queda de posição no ranking.

Porém, cabe ressaltar que em 2017 o Ceará foi líder em faturamento entre estados exportadores de crustáceos e peixes. Com destaque a mesorregião do Jaguaribe, segundos dados do IPECE (2017) foram comercializados US $\$ 54,2$ milhões. Em volume exportado, o Ceará ficou na terceira posição, com 4,8 mil toneladas. Do total, 3 mil toneladas são de peixes congelados e 1,7 mil são de crustáceos, sobretudo lagosta. Vale ressalta que a Microrregião do Baixo Jaguaribe, apresenta municípios mais relevantes da produção de fruticultura irrigada, sendo um dos grandes produtores para exportação de culturas como o melão, verificou-se o crescimento do comércio varejista com a consolidação das atividades do perímetro irrigado.

A atividade aquífera favorece a retirada de lagosta e camarão. Em cativeiro é produzida a lagosta. São expressivas as criações de bovinos, suínos, aves, ovelhas e cabras (VERAS, 2010). A Figura 01 apresenta a distribuição espacial da participação das microrregiões segundo o IEPC, em 2007 (lado esquerdo) e 2017 (lado direito). 
Figura 01 - Distribuição espacial da participação das microrregiões segundo o IEPC - 2007 e 2017

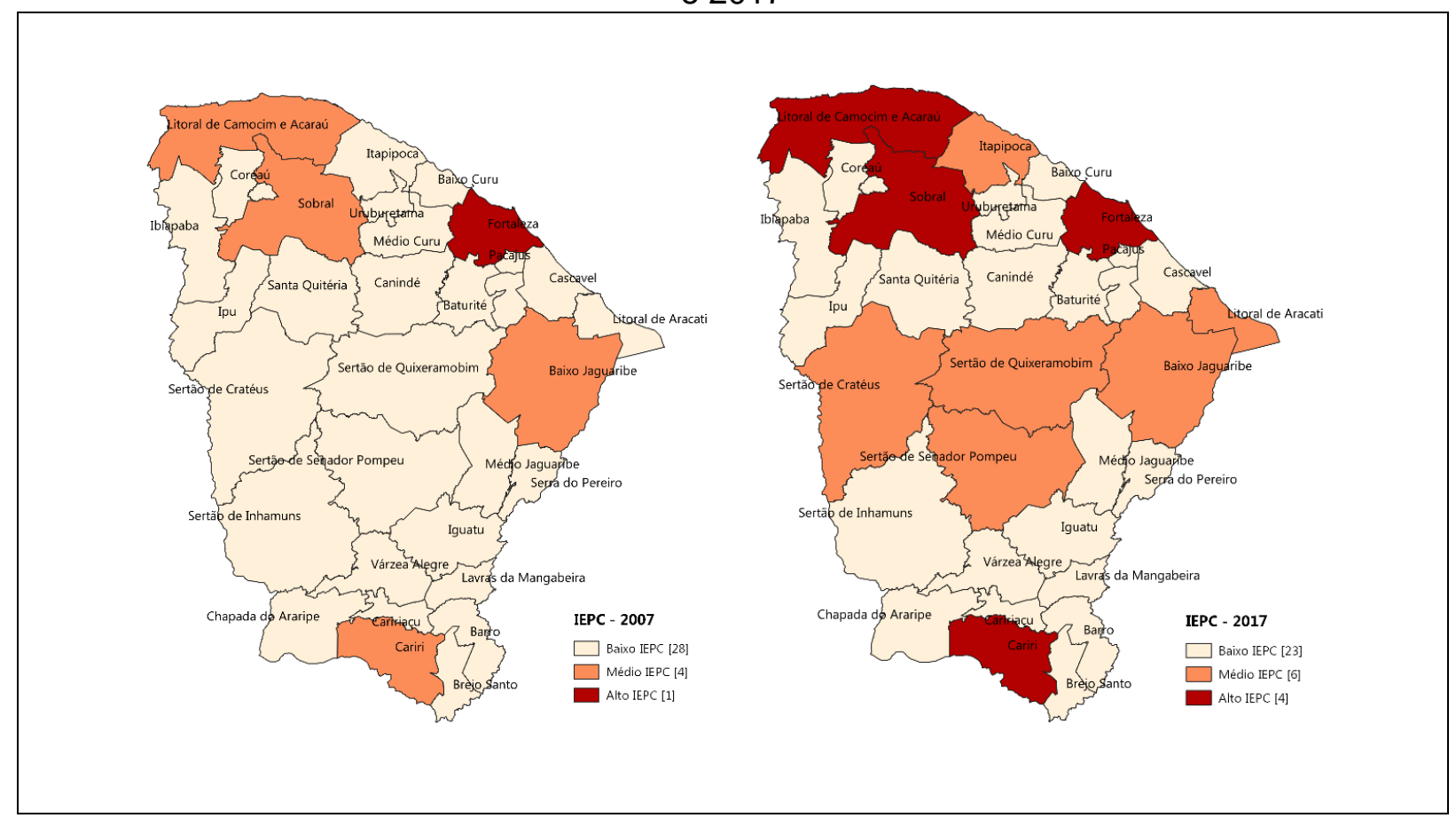

Fonte: Elaboração própria a partir dos resultados.

A modificação no último ano de estudo, aponta a mesma conclusão, uma ampliação da participação econômica das microrregiões interioranas. Nota-se uma melhoria na distribuição espacial em termos de estrutura produtiva, ou seja, houve entre esse período significativas repercussões econômicas nas microrregiões interioranas. Como é o caso do Sertão de Quixeramobim, Sertão de Crateús, Sertão de Senador Pompeu, Baixo Jaguaribe e Litoral de Aracati, na parte central do estado. Muito embora o movimento de ampliação da participação dos municípios fora da região metropolitana venha se verificando, ainda é forte o grau de concentração das atividades produtivas na faixa litorânea do estado.

Os programas e ações do PRODETUR/NE sob esta designação tem como centro o Polo Turístico de Jijoca de Jericoacoara, mas os investimentos abrangem municípios como Caucaia, São Gonçalo do Amarante, Paracuru, Itapipoca, Amontada, Trairi, Itarema e Camocim. Nos municípios do interior do estado, sobressai-se o já conhecido conjunto formado pelos polos mais dinâmicos como Sobral, na região Noroeste, o aglomerado Crato-Juazeiro do Norte-Barbalha situado mais ao Sul e Iguatu, na Microrregião de Iguatu.

\section{Considerações Finais}

Por meio do cálculo o IEPC, no ano de 2007, 84,8\% das microrregiões apresentou baixo grau de estrutura produtiva e do total, apenas $3 \%$, o que equivale 
a uma microrregião apresentou alto grau de estrutura produtiva. Em 2017, sobe para quatro o número de microrregiões com alto índice de estrutura produtiva, totalizando $12,1 \%$. Contudo, a maioria $(69,7 \%)$ representam microrregiões de baixo GCE e se concentra, sobretudo no interior do estado.

Os polos mais desenvolvidos em termos de estrutura produtiva se concentraram na faixa litorânea em 2007, contudo, nota-se um espraiamento das atividades produtivas em 2017, levando a crer que o processo de interiorização das atividades econômicas e produtivas está cada vez mais inserido na dinâmica atual do capitalismo. Vale destacar, que as políticas de interiorização do desenvolvimento, tem suscitado transformações econômicas e uma distribuição espacial mais homogênea nas microrregiões sob a lógica da acumulação capitalista.

Desse modo, tem-se a acepção de que entre 2007 e 2017 foram evidenciadas mudanças na estrutura produtiva e nas suas espacialidades dentro do território cearense, corroborando-se aqui com os resultados apontados pela análise fatorial, comprovando a validade da assertiva levantada na hipótese deste estudo.

Por fim, o IEPC mostrou que a maioria das microrregiões nos dois anos em análise possui baixos níveis de crescimento econômico. Desse modo, a situação das mesmas deve ser tratada com maior atenção pelos formuladores e gestores de políticas públicas quando se almeja priorizar regiões mais atrasadas em termos de estrutura produtiva. Outro resultado relevante foi ressaltar haver diferenças de estruturas produtivas entre as regiões $A$ (litoral) e $B$ (interior), sendo que às microrregiões situadas nas próximas da faixa litorânea apresentam maior IEPC do que às demais. Sugere-se a continuação de estudos que possibilitem analisar a estrutura produtiva nos anos subsequentes, verificando possíveis alterações nesse quadro e apontando soluções para redução das disparidades intraestadual.

\section{REFERÊNCIAS}

ACCIOLY, V. M. A metrópole e o impacto das políticas públicas na expansão urbana: Fortaleza entre 1980 e 2008. Artigo apresentado no Encontro de Geógrafos da América Latina (EGAL), Montevideo. 2009.

ALVES, Denis Fernandes. Estrutura produtiva e desigualdade intermunicipal de renda no Brasil: uma abordagem regional. 2020. 204f. Dissertação (Mestrado em Economia) Centro de Ciências Sociais Aplicadas, Universidade Federal do Rio Grande do Norte, Natal, 2020.

ALVES, Denis Fernandes et al. Estrutura Produtiva nas Mesorregiões do Nordeste Brasileiro: uma análise fatorial. Informe Gepec, v. 22, n. 2, p. 81-98, 2018. 
ALVES, Denis Fernandes et al. Desenvolvimento Humano do estado do Ceará: uma análise territorial a partir do IDHM. Economia \& Região, v. 5, n. 2, p. 23-41, 2017.

AMORA. Z. B. Aspectos históricos da industrialização do Ceará. In: SOUZA, S. (org.) História do Ceará. Fortaleza: Fundação Demócrito Rocha. 1994.

BRANDÃO, C. A.; OLIVEIRA, H. S. Divisão inter-regional do trabalho no Brasil nos anos 90: perdas de quantidade e qualidade nos investimentos, empregos e instrumentos de regulação. RIBEIRO, ACT et al, p. 355-389. 2005.

CANO, W. Desequilíbrios regionais e concentração industrial no Brasil, 1930-1995. 2. ed. Campinas, SP: UNICAMP, 1998. 421p.

DEDECCA, C. S.; ROSANDISKI, E. N. Recuperação econômica e geração de empregos formais. Parcerias Estratégicas, 22:169-190. 2006.

FERREIRA JÚNIOR, S.; BAPTISTA, A. J. M. S.; LIMA, J. E. A modernização nas microrregiões do Estado de Minas Gerais. RER, Rio de Janeiro, v. 42, n. 01, p. 73-89, jan/mar. 2004.

FIGUEIREDO FILHO, D. B.; SILVA JÚNIOR, J. A. Visão além do alcance: uma introdução à análise fatorial. OPINIÃO PÚBLICA, Campinas, v. 16, n. 1, p. 160-185. 2010.

GUIMARÃES NETO, L. Introdução à formação econômica do Nordeste. Recife, Fundaj/Massangana. 1989.

HADDAD, P. R. Os novos polos regionais de desenvolvimento. Rio de Janeiro: INAE. 1989.

HAIR, J. F. et al. Analise Multivariada de dados. 5ª Ed. São Paulo: Brookman. 2007.

HOFFMAN, R. A dinâmica da modernização da agricultura em 157 microrregiões

homogêneas do Brasil. Revista de Economia e Sociologia Rural. Brasília, v.30, n.4, p.271-290, out-dez, 1992.

IPECE - Instituto de Pesquisa e Estratégia Econômica do Ceará. Ipece Conjuntura 2017. Boletim da Conjuntura Econômica cearense, referente aos resultados do 4 o trimestre de 2017. Fortaleza/CE. v.6, n.4, 2017.

JOHNSON, R. A.; WICHERN, D. W. Applied multivariate statistical analysis. Prentice Hall. 1992.

LEMOS, J. J. S. Indicadores de Degradação no Nordeste Subsumido e Semiárido. Revista SOBER, p.1-10. 2000.

LIMA, V. M. A.; MAIA, K. Índice de desenvolvimento socioeconômico dos municípios sulmato-grossenses para 2010. Revista Brasileira Eco. de Emp. n. 15, v. 2, p. 83-103. 2015.

LIMA JÚNIOR, F. O. Estrutura produtiva e rede urbana no Estado do Ceará durante o período de 1980-2010. Campinas. SP: Instituto de Economia da UNICAMP (Tese de Doutorado). 264p. 2014.

MATA, H. et al. Padrão e determinantes do desenvolvimento econômico e social dos municípios do Estado da Bahia: a dicotomia rural - urbano. In: Congresso da SOBER, XLVI, 2008. SOBER: Rio Branco, 2008.

MELO, C.; PARRÉ, J. Índice de desenvolvimento rural dos municípios paranaenses: determinantes e hierarquização. Revista de Economia e Sociologia Rural, v. 45, n. 02, p. 329-365. 2007.

MISSAGGIA, S. Z. Desenvolvimento humano na mesorregião centro ocidental-RS: um estudo utilizando a análise fatorial. Monografia de especialização apresentada ao curso de especialização em estatística e modelagem quantitativa da Universidade Federal de Santa Maria (UFSM, RS). 2012. 
MORAIS, Gabriel Alves de Sampaio; SOBREIRA, Diogo Brito; LIMA, João Eustáquio. Padrão e determinantes da infraestrutura urbana das microrregiões brasileiras. Geosul, v. 33, n. 66, p. 262-291, 2018.

MORAIS, Micaelson Lacerda; MACEDO, Fernando Cézar de; LIMA JÚNIOR, Francisco do O' de. Ceará: Economia, Urbanização e metropolização. Crato, CE: RDS Editora, 2014

PALLANT, J. SPSS Survival Manual. Open University Press, 2007.

PEREIRA JÚNIOR, Edilson. O processo de industrialização e as novas articulações cidadeurbano-região. Anais do XII Encuentro de Geógrafos da América Latina. Montevidéo, 2009.

PEROBELLI, F. et al. Planejamento Regional e Potenciais de desenvolvimento dos municípios de Minas Gerais na região em torno de Juiz de Fora: Uma aplicação de análise fatorial. Revista Nova Economia. v. 9, n.1, jul. 1999.

PINHEIRO, Tiago Cisalpino. Hierarquia urbana e situação fiscal dos municípios brasileiros. Revista Brasileira de Estudos Regionais e Urbanos, v. 3, n. 1, 2009.

REZENDE, M. L.; FERNANDES, L. P. S.; SILVA, A. M. R. Utilização da Análise Fatorial para determinar o potencial de crescimento econômico em uma Região do Sudeste do Brasil. Revista Economia e Desenvolvimento, n. 19. 2007.

SENNETT, R. A corrosão do caráter: consequências pessoais do trabalho no novo capitalismo. 4. ed. Rio de Janeiro: Record. 2000.

SILVA FILHO, L. A.; QUEIROZ, S. N. Políticas de concentração ou desconcentração industrial no território cearense? APGS, Viçosa, v. 1, n. 4, p. 1-22, out./dez. 2009.

SILVA FILHO, L. A.; QUEIROZ, S. N. Indústria têxtil: uma análise do emprego formal em Santa Catarina vis-à-vis o Ceará - 1998/2008. Perspectiva Econômica, v. 7, n. 2, p. 64-77, jul./dez. 2011.

SOUSA, F. J. P. Transformações Políticas e Institucionais no Ceará: repercussões nas finanças públicas do Estado. Rev. Econ. do Nordeste. Fortaleza, v. 38, n. 4, out-dez. 2007.

SHIKIDA, P. F. A. Desenvolvimento socioeconômico e agroindústria canavieira no Paraná. Revista de Política Agrícola, v. 19, n. 3, p. 67-82. 2010.

VASCONCELOS, J. R.; ALMEIDA, M. B.; SILVA, A. B. Ceará: Economia, Finanças Públicas e Investimentos nos anos de 1986 a 1996. Texto para discussão, n. 627. Brasília, fev. 1999.

VERAS, Ana Odilia de Carvalho. Impactos Socioambientais no Estuário do Rio Jaguaribe: o Caso da Cidade de Aracati-Ce. 2010.

XERXENEVSKY L. L; FOCHEZATTO, A. Índice relativo de desenvolvimento socioeconômico dos municípios do litoral norte do Rio Grande do Sul: uma aplicação da análise fatorial. Boletim Geográfico do Rio Grande Do Sul. Porto Alegre (RS). Ed. 25, p. 31-55. 2015.

\section{NOTAS DE AUTOR}

\section{CONTRIBUIÇÃO DE AUTORIA}

Denis Fernandes Alves - Concepção, coleta de dados, análise de dados, elaboração do manuscrito, participação ativa da discussão dos resultados e aprovação final.

Francisco do O' de Lima Júnior - Concepção, participação ativa da discussão dos resultados, revisão e aprovação da versão final do trabalho.

Wellington Ribeiro Justo - Participação ativa da discussão dos resultados, revisão e aprovação da versão final do trabalho. 


\section{FINANCIAMENTO}

FUNCAP - Fundação Cearense de Apoio ao Desenvolvimento Científico e Tecnológico.

\section{LICENÇA DE USO}

Este artigo está licenciado sob a Licença Creative Commons CC-BY. Com essa licença você pode compartilhar, adaptar, criar para qualquer fim, desde que atribua a autoria da obra.

\section{HISTÓRICO}

Recebido em: 11-10-2019

Aprovado em: 15-06-2020 